COUTINHO, Eduardo. Literatura comparada. Reflexóes. São Paulo, Annablume, 2013.

\title{
Mauricio Silva
}

Universidade Nove de Julho São Paulo, SP, Brasil

Professor titular de Literatura Comparada da Universidade Federal do Rio de Janeiro (UFRJ), e de diversas universidades estrangeiras, além de membro fundador e ex-presidente da Associação Brasileira de Literatura Comparada (ABRALIC), Eduardo Coutinho publica em 2013 um livro que, de certo modo, é uma espécie de continuação do livro que publicou há dez anos (Literatura comparada na América Latina: ensaios), como o próprio autor lembra em seu prefácio. Privilegiando aspectos do comparatismo literário na segunda metade do século XX e no contexto da América Latina, Coutinho elenca alguns textos publicados anteriormente em revistas acadêmicas ou coletâneas de estudos teóricos sobre o tema. Pode-se dizer que são três os temas principais analisados e discutidos pelo autor nesse seu novo livro: 1. o comparatismo literário em geral e suas relações com áreas afins (crítica literária, historiografia literária, tradução etc.); 2 . a relação entre a Literatura Comparada e o advento do pós-modernismo/pós-modernidade; 3. a presença da Literatura Comparada na América Latina, problematizando essa proximidade.

Em relação ao primeiro tema, Coutinho destaca - em "Literatura comparada: reflexôes sobre uma disciplina acadêmica" (2013: 11-31) - o fato de que a Literatura Comparada tem como marca fundamental o conceito de transversalidade, tanto em relação à fronteira entre naçôes e idiomas quanto em relação aos limites entre áreas do conhecimento. Retoma, nesse sentido, alguns momentos do comparatismo literário, como o de Guyard (La littérature comparée, 1951), com o predomínio dos binarismos da Escola Francesa ou o de Pichois e Rousseau (La littérature comparée, 1967); como o de Owen Aldridge (Comparative literature, 1969), com uma perspectiva mais abrangente, relacionada à interdisciplinaridade, da Escola Americana ou o de Henry Remak (Comparative literature, 1961). Para o autor, a noção de transversalidade, contudo, se faz mais explícita na inter-relação da literatura com outras áreas do conhecimento, tendência que vem se ampliando cada vez mais atualmente. Trata-se, portanto, de uma das principais preocupaçóes teórico-metodológicas dos pesquisadores da área, repercutindo, no presente, a contribuição dos Estudos Culturais e Pós-Coloniais no campo do comparatismo, que desvia a ênfase no literário (ainda presente mesmo na Escola Americana) para outras 
áreas do saber: hoje, pode-se dizer, prevalece um sentido de interdisciplinaridade entre culturas.

Já em "Criação e crítica: reflexões sobre o papel do crítico literário" (2013: 99-108), Coutinho trata do papel e da natureza da Crítica Literária, afirmando que "é possível intuir-se até certo ponto a qualidade de uma obra, mas não estabelecerem-se critérios objetivos de avaliaçáa” (2013: 101). Essa situação se torna mais evidente com questóes trazidas pela pós-modernidade, levando a Crítica a "mergulha(r) em terreno pantanoso, sem parâmetros definidos" (2013: 104), resultando numa "espécie de relativização segundo a qual os critérios de avaliação passam a oscilar de acordo com o olhar adotado e o locus de enunciação do estudioso" (2013: 105). Reflexôes análogas a esta o autor faz em relação à tradução, quando - em "Literatura comparada e tradução no Brasil: breves reflexōes” (2013: 109-119) - lembra que a tradução vem sendo tradicionalmente considerada uma atividade secundária, situação que sofre significativa transformação com o advento dos Estudos Culturais, os Estudos Pós-Coloniais e a Desconstrução: a Tradução (ou o que passou a se chamar Estudos de Tradução) torna-se mais valorizada, destacando diferenças históricas e culturais, rompendo com a hierarquia entre o original e o traduzido: "dentro dessa perspectiva, traduzir se torna estabelecer um diálogo, e não apenas no nível linguístico, mas principalmente no nível cultural" (2013: 112); ou quando lembra - em "O comparatismo nas fronteiras do conhecimento: contradiçóes e conflitos" (2013: 121-133) - que, ao contrário da lógica iluminista, a pós-moderna considera o conhecimento como algo instável, desqualificando a noção de fronteira e a compartimentação de saberes e valorizando noçôes como as de interdisciplinaridade e transdisciplinaridade e, finalmente, colocando em xeque o "privilégio concedido ao texto literário" (2013: 123) pelo comparatismo tradicional. Amplia-se, assim, a reflexão em torno da produção literária, incentivando suas relaçôes extrínsecas com contextos históricos, sociológicos, psicológicos etc. e promovendo o diálogo com as demais disciplinas: "as fronteiras, embora tênues, que ainda marcavam o comparatismo foram amplamente esgarçadas, e a disciplina [Literatura Comparada], além de absorver elementos de outras e de prestar subsídios a suas elaborações, tem-se erigido como espaço de reflexão sobre a produção, a circulação e a negociação de objetos e valores, contribuindo assim de maneira decisiva para a esfera mais ampla dos Estudos de Humanidades" (2013: 127). Tem-se, desse modo, que os princípios tradicionais do comparatismo literário foi combatido pelos Estudos Culturais, além de ter muitos de seus pressupostos questionados pelos Estudos Pós-Coloniais.

Em relação ao segundo tema, o autor - em "Revisitando o pós-moderno" (2013: 33-58) - começa distinguindo pós-modernidade de pós-modernismo, 
nos seguintes termos: "encaramos a pós-modernidade como um fenômeno geral, uma Weltanschauung, que implica uma série de transformaçóes no panorama cultural ocidental, e o pós-modernismo como um estilo de época, marcado por traços mais ou menos definíveis, que refletem tais transformações" (2013: 34). O autor se propóe a abordar esses conceitos no contexto latino-americano (em particular, no brasileiro), tendo como eixo da discussão a tensão entre identidade e diferença. Lembra, por exemplo, que o Modernismo, ao se opor à representação realista, instaura uma crise da representação, conferindo à obra de arte uma autonomia que a dissociava do contexto histórico e a destituía de preocupaçóes fora da ordem estética, ligandose à racionalidade. Após a Segunda Guerra Mundial, essa perspectiva começa a apresentar sinais de exaustáo, e a partir dos anos 50-60 seus pressupostos começam a ser colocados em xeque pelo que, depois, se convencionou chamar de pós-modernismo. A obra de arte, então, deixa de ser modelar, rompendo-se a separação entre o erudito e o popular e revalorizando o contexto histórico: "partindo da consciência de sua condição de discurso e do reconhecimento de seu caráter histórico, o pós-moderno póe em xeque princípios como valor, ordem, significado, controle e identidade, que constituíram premissas básicas do liberalismo burguês, e se erige como um fenômeno fundamentalmente contraditório, marcado por traços como o paradoxo, a ambiguidade, a ironia, a indeterminação e a contingência. Desaparece, assim, a segurança ética, ontológica e epistemológica, que a razão garantia no paradigma moderno e o pós-moderno se insurge como o reino da relatividade" (2013: 40). E completando:

O fenômeno pós-moderno se revela justamente naquelas obras em que se vislumbra uma pluralidade de linguagens, modelos e procedimentos, e onde oposiçóes como aquelas entre realismo e irrealismo, formalismo e conteudismo, esteticismo e engajamento político, literatura erudita e popular cedem lugar a uma coexistência em tensão desses mesmos elementos. Utilizando-se da paródia e de outros recursos técnicos desestabilizadores, o Pós-Modernismo desestrutura figuras e vozes narrativas estáveis e problematiza toda a noção tradicional de conhecimento histórico, pondo em questão ao mesmo tempo todas as instituiçóes e sistemas que constituem as fontes básicas de significado e valor da tradição estética ocidental. (2013: 41)

Analisando o fenômeno do Pós-Modernismo historicamente, Coutinho lembra que, nos anos 1960, ele se afirma como um movimento de contestação e irreverência, ligando-se aos movimentos de arte pop e, de certo modo, revitalizando alguns movimentos de vanguarda e dando-lhes uma roupagem mais norte-americana; nos anos 1970 e 1980, o conceito se alia a uma visão mais crítica da realidade, para, nos anos 1990, a participação de minorias conferir- 
lhe um sentido próximo da então chamada literatura pós-colonial (e, também, dos Estudos Culturais), retomando, além disso, a questão da representação e do sujeito, fazendo com que o Pós-Modernismo adquira um sentido mais político, na medida em que passa a contestar toda sorte de etnocentrismo. Para o autor, no contexto latino-americano, o conceito de Pós-Modernismo remete, principalmente, à produçấo artística pós-segunda metade do século XX.

Finalmente, em relação ao terceiro tema, começa tratando - em "América Latina: o móvel e o plural” (2013: 59-67) - do termo América Latina, desde a chegada dos europeus associado à ideia de colonização e, na sequência, vinculado a processos de independência e de afirmação de identidades locais. A ideia passa por algumas ampliaçôes semânticas, incluindo o Brasil e, posteriormente, a América Central, caráter mais inclusivo que vai se afirmando também com as novas correntes teóricas de reflexão acerca da cultura (Nova História, Estudos Culturais, Estudos Pós-Coloniais etc.).

Em "Transferências e trocas culturais na América Latina" (2013: 69-84), afirma que a Literatura Comparada, desde o início, surge "como um conceito relacional, ou, melhor, como o estudo das relaçóes entre produçóes literárias distintas" (2013: 69), diferenciando-se das literaturas nacionais por ter como objeto "produtos literários, e por extensão culturais, distintos, caracterizando-se como o estudo dos contatos, trocas, intercâmbios e embates entre tais produtos, ou, para colocar em termos mais acadêmicos, como o estudo, mais ou menos sistemático, dos diálogos entre culturas" (2013: 70). Após uma fase de ênfase quase que exclusiva no texto literário (como se verifica na Escola Americana), o advento dos Estudos Culturais ressaltou, no âmbito do comparatismo literário, aspectos mais gerais da literatura, contribuindo para "situar a reflexão literária num âmbito mais geral que diz respeito à cultura de uma ou de várias sociedades" (2013: 71). Essa postura contribui significativamente para uma compreensão mais larga da realidade latino-americana, quase sempre vista numa dependência da europeia, prejudicando leituras que a pudessem contemplar como um "espaço distinto do eurocentrismo" (2013: 73). É o que propõem teorias como as de heterogeneidade cultural (Cornejo Polar), culturas híbridas (Canclini), heterogeneidade cultural heterônoma (Brunner), pós-ocidentalismo (Mignolo) e outras, novos modos e novas estratégias de leitura diante de um espaço cultural plural. Nesse contexto, o atual papel da Literatura Comparada (não, evidentemente, a tradicional, que aborda as relaçóes a partir do modelo europeu) torna-se fundamental, no sentido de promover "um comparatismo que permita o contraste entre distintas práticas sociais discursivas procedentes de culturas diferentes que convivem em um mesmo espaço-tempo" (2013: 89). Trata-se, assim, de um comparatismo que reconhece a existência de práticas discursivas próprias de contextos colonizados; reconhece, portanto, o conheci- 
mento produzido pelo outro: "trata-se, em última instância, de um comparatismo situado no contexto de onde olhamos, que, ao contrastar as produçóes locais com as provenientes de outros lugares, instaure uma reciprocidade cultural, uma interação plural, que induz conhecimento a partir do contacto com outras culturas" (2013: 83).

Já em "Cartografias literárias na América Latina: algumas reflexōes" (2013: 85-108), o autor afirma que a nova historiografia literária vem procurando formular um "discurso fundamentalmente plural, heterogêneo, representado por múltiplos sujeitos, que dê conta da diversidade dos universos representados" (2013: 86), desafiando os historiadores literários a produzir um relato inclusivo. Assim, o discurso nacional contemporâneo precisa ser um espaço de negociação e conversação pelos sujeitos que compóem o cenário da nação, sendo colocada em suspeição a ideia de uma versão oficial e única dos fatos. No âmbito da historiografia literária, portanto, "a busca da construção de uma história democrática da produção literária de uma nação [deve] passar necessariamente pelo questionamento [do] cânone [oficial], sobretudo com seus vieses excludentes e elitistas" (2013: 87). Nesse processo de redimensionamento da historiografia literária, os Estudos Culturais desempenham papel relevante, incluindo entre as preocupaçóes daquela dos discursos e saberes, ultrapassando as fronteiras do que até então era considerado literário: "agora, ao lado do exame do texto, bem como dos gêneros, estilos e topos, que por tanto tempo alicerçaram as obras de História da Literatura, torna-se relevante também a análise do campo em que se produziu a experiência literária, e o contexto de recepção da obra é tratado com a mesma importância do de produção" (2013: 89). Nesse novo contexto, o discurso da historiografia literária passa a ser visto como uma construção: "Como são muitos os sujeitos sociais que passam a narrar a história, e esses sujeitos procedem de origens distintas, o idioma canônico deixa de ser a única forma de expressão de uma determinada comunidade, passando a aceitar outras linguagens, e rompendo-se, assim, com toda sorte de visão monolítica do real" (2013: 90). Nesse contexto ainda, em que a episteme pós-moderna coloca em xeque os discursos autoritários, a historiografia literária vem adquirindo uma nova face, que se organiza tanto no eixo temporal (substituindo uma noção de progressão/evolucionismo pela de simultaneidade) quanto no espacial (considerando regióes culturais até então excluídas do cânone), além de um alargamento das formas literárias, incorporando algumas tradicionalmente excluídas da historiografia (como o corrido mexicano ou o cordel brasileiro).

Por fim, em "Velhas dicotomias que se enlaçam: voz/letra, público/privado no universo latino-americano" (2013: 135-145), o autor trata, entre outras coisas, da reverência à cultura letrada no processo de colonizaçáo da 
América Latina ("A palavra falada, a voz, pertencia ao reino do inseguro e do precário; e a escritura, ao contrário, possuía rigidez e permanência, um modo autônomo que arremedava a eternidade", 2013: 138).

Pode-se dizer que seu livro é uma consciente e bem fundamentada apologia dos ganhos e achados oferecidos ao comparatismo literário - em vários de seus níveis de atuação prática - pelas novas teorias que, na contemporaneidade, recebem a designação de Estudos Culturais e Pós-Coloniais e abordagens congêneres, dentro do que o autor chama de episteme pós-moderna.

Mauricio Silva possui doutorado e pós-doutorado em Letras Clássicas e Vernáculas pela Universidade de Sáo Paulo. Professor do Programa de Mestrado e Doutorado em Educação, na Universidade Nove de Julho (São Paulo), é autor dos livros $A$ Hélade e o Subúrbio. Confrontos Literários na Belle Époque Carioca (São Paulo, Edusp, 2006); A Resignação dos Humildes. Estética e Combate na Ficção de Lima Barreto (São Paulo, Annablume, 2011), entre outros. É organizador da coleção de Literatura Brasileira Contemporânea, pela Editora Terracota, atualmente com três títulos publicados. Endereço para correspondência: Rua General Rondon, 44 - Ap. 10 - São Paulo SP-01204-010. E-mail: maurisil@gmail.com. 